\title{
A Multi-Objective Optimization Model for Designing Business Portfolio in the Oil Industry
}

\author{
Amir Kamran Kiamehr \\ Faculty of Management and Economics, \\ Department of Industrial Management, \\ Tarbiat Modares University, Tehran, Iran
}

\author{
Adel Azar \\ Faculty of Management and Economics, \\ Department of Industrial Management, \\ Tarbiat Modares University, Tehran, Iran \\ azara@modares.ac.ir
}

\author{
Mahmoud Dehghan Nayeri \\ Faculty of Management and Economics, \\ Department of Industrial Management, \\ Tarbiat Modares University, Tehran, Iran
}

\begin{abstract}
Designing a business portfolio is one of the key decisions in developing corporate strategy. Most of the previous models are either non-quantitative or financial with an emphasis on optimizing a portfolio of investments or projects. This research represents a multi-objective optimization model that firstly, employs quantitative methods in strategic decisionmaking, and secondly, quantifies and considers non-financial, strategic variables in problem modeling. In this regard, links between businesses within a portfolio have been classified into four groups of market synergy, capabilities synergy, parenting costs, and sharing benefits, and have been structured as a conceptual model. Although the conceptual model can be applied to various industries, it is formulated for designing the portfolio of multi-business companies in Iran oil industry. The model has been solved for three cases by NSGA-II algorithm and strategic insights have been explored for different corporate types.
\end{abstract}

Keywords-corporate strategy; business portfolio; multi-objective optimization; oil industry

\section{INTRODUCTION}

The historical trend about how business portfolios form represents the tendency of companies to engage in diverse businesses during the 50's to 80's and the emergence of large multi-purpose companies; then, the trend reversed from the 80's to now by focusing on a major and specialized business, or ultimately a portfolio of "related" businesses [1]. Over the past decades, how to define a business portfolio has been one of the key issues in strategic planning for businesses. Studies in this regard have been developed in areas such as diversification, vertical integration, outsourcing, M\&A, partnerships, and allocation of resources among businesses [2]. The studies and models in this area can be divided into two main groups. The first group includes famous models such as GE/McKinsey matrix and Boston Consulting Group growth/share matrix [3, 4]. They consider entering or not entering into a business with limited and conceptual criteria such as industry attractiveness and competitive status. On the contrary, the second group of financially-focused studies are seeking to maximize profit or minimize risk of investment portfolios, like numerous studies based on Markowitz's famous model for portfolio optimization [5]. However, it seems that the studies and the developed models in this area are faced with weaknesses in terms of efficiency for strategic decision-making because the first group of models is conceptual and high level and they cannot provide the necessary analysis to support management decisions. Meanwhile, the second group is suitable for optimizing stock and investments portfolios while the components in design of a business portfolio cannot be described only in the context of financial indicators. In order to meet this need, this research is an attempt to develop a quantitative model that can support strategic decision-making at the corporate level for designing a business portfolio.

\section{LITERATURE REVIEW}

Over the past decades, two key levels of strategy have been defined for organizations. First, "corporate strategy" that defines the territory of the corporation and shows businesses which corporates should enter into. Secondly, "business strategy" that deals with how corporations compete within an industry or market [2,6]. Authors in [7] structured approaches related to corporate strategy in four groups including portfolio management, restructuring, transferring skills, and sharing activities. Each approach is based on a different mechanism for value adding by the corporation. Portfolio management is based on diversification, mainly through the acquisition of attractive businesses, providing capital, goal setting, and monitoring of business outcomes. In restructuring approach, the focus is on potentials of business units that are prone to change. In skills transfer approach, focus is on synergy and the transfer of skills and knowledge among the value chain of businesses. In sharing activities approach, the value is created through shared operations in value chain such as the use of a shared distribution system or creation of competitive advantage through cost reduction. In the above structure, the first two approaches are based on the creation of value through the association of the parent company with each of the independent businesses, while the other two concepts are focused on extracting value through the link between businesses and their synergy. In a general view, corporate strategy can be considered as a decision on product range and vertical range, which is discussed in the literature in terms of diversification and vertical integration, respectively. Evidence suggests that in the 1950s and 1980s, companies began to design diverse and unrelated business portfolios, they set up multifunctional companies and diversified businesses that ultimately led to the formation of so-called "conglomerates". Based on the 
experience, the above process was reversed from 1980, and in that period unprofitable businesses were left aside. Then, refocusing has once again been highlighted on major and specialized businesses or the formation of a portfolio of related businesses [2]. In some studies, it has been shown that the focus strategy has a positive impact on the corporate's value for shareholders, but some argue that corporate devaluation after diversification is due to the ownership of new businesses at lower prices during the diversification process [8]. Despite decades of debate in this area, portfolio design and issues like the amount of diversification and vertical integration are still at the heart of the attention of businesses and researchers [9-11]. The persistence of these questions is because of the fact that although there are evidence of failure of many diversification strategies in the age of diversification, there are still undeniable advantages for diversity including the possibility of growth (in the sense of going beyond the current industry's boundaries), risk reduction due to its distribution in a portfolio of businesses, savings by globalization, benefit of the parent company, and reaching an internal market $[2,12,13]$. It can be concluded that the effectiveness of diversification is subject to conditions [14, 15].

Moreover, importance and complexity of decision making on the business portfolio in various industries varies according to the volume of the required investment, the variety of components in the value chain, and the existing risks. In this regard, the oil industry can be ranked high. For example, in the field of exploration and production, decisions are very complex and risky due to the uncertainty and large number of factors involved. The selection of the optimal portfolio of projects in this section is influenced by diverse topics including corporate strategies and constraints, reservoir geology assessment, engineering data, economic forecasts, financial model, and regulatory aspects [16]. In this regard, mathematical optimization models have been widely developed for the oil industry by researchers. Author in [17] used genetic algorithm for optimizing portfolio in the oil and gas industry. In his model, the portfolio is composed of projects, not businesses. In other words, it is the investment portfolio of the oil company. $\mathrm{He}$ also argues the advantages of the portfolio theory for this purpose. It enables decision makers to consider set of available opportunities beyond merely examining the independent economic indicators of each project and approving or rejecting investment in it. It also gives them the opportunity to reach a portfolio of projects with maximum returns at a certain level of risk.

In general, mathematical optimization models offered for the oil industry can be classified into three strategic areas of portfolio selection, tactical planning such as production planning, and operation such as well optimization [18]. In this framework and given the complexity of decision making in the oil industry, portfolio design models have always been considered, used and developed $[19,20]$. New tools such as the theory of real options have also been used for this purpose [21]. However, in previous researches on portfolio optimization, financial approaches based on Markowitz's foundation have been applied. In the oil industry, the use of portfolio concept and portfolio theory has focused primarily on portfolio selection methods for projects and assets. Hence, quantitative models for designing a business portfolio that consider strategic concepts have not developed in this industry.

\section{DESIGNING MODEL}

\section{A. Conceptual Model}

In order to develop a model that provides the optimal business portfolio, we first need to determine the goals we are seeking for optimization. According to the existing literature and workshops organized by a focus group of experts, four main objectives were identified, namely maximum profitability, minimum investment, maximum growth and maximum profit robustness (minimum profitability risk). The first two objectives can be integrated as the economic value added (EVA) concept. Economic value added, one of the most widely used criteria in economic profitability models [22], is a good indicator of differentiation between portfolio with higher returns than lower returns [23]. Despite fundamental similarities, EVA provides better strategic and management illustration of economic returns for a company compared to NPV which is basically developed to model the profitability of a project [24]:

$$
E V A=\left(\frac{P}{C}-W A C C\right) \times C
$$

In this equation, $\mathrm{P}$ is net operating profit after tax, $\mathrm{C}$ is invested capital, and WACC is weighted average cost of capital. Accordingly, it can be said that each of the businesses in the portfolio at each period creates an economic value added independently and this trend of value adding during the periods leads to growth and robustness. Based on existing literature, we formulate this cross-business impact as follows:

1. Capability synergy: A business in a portfolio can affect the level of capability in another business by different ways, such as sharing activities or utilizing existing knowledge and expertise.

2. Market share synergy: Participating in a business can change the market of another business. For example, creating a market for another business or prevent its presence in a market, because of legal constraints.

3. Parenting costs: Having a portfolio of businesses instead of an individual business can create costs such as overheads, management costs or so-called holding costs, which are called "parenting costs" in this research.

4. Sharing benefits: Engaging in a business can save money in the cost structure of another business, which is called "sharing benefits". These benefits can be realized in a variety of ways such as using shared resources or services, or increasing bargaining power with suppliers.

Therefore, we can present a high-level, conceptual model (Figure 1) in which the value creation of any business is a function of the revenue, cost, and profitability mechanisms of the business. These factors are independently influenced by the internal variables (capabilities) and the external variables (market) of each business, while being systematically affected by the link between the businesses in the fourfold form above. 


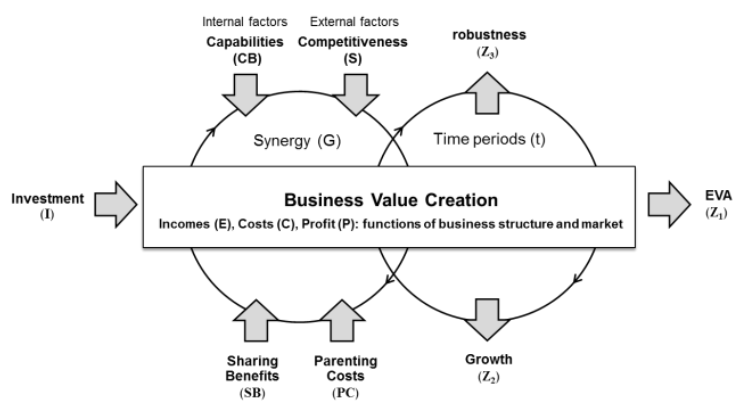

Fig. 1. Conceptual model

Now, if $x$ represents the presence or absence in a business, the above model can be formulated for business $i$ in the period $t$ in the form of the following mathematical relations:

$$
\begin{aligned}
& \operatorname{Max} Z_{1}=f\left(E V A_{i, t}\right) \\
& \operatorname{Max} Z_{2}=f\left(\frac{d E_{i, t}}{d t}\right) \\
& \operatorname{Min} Z_{3}=f\left(\sigma_{P_{i, t}}^{2}\right) \\
& E V A_{i, t}=f\left(P_{i, t}, I_{i, t}\right) \\
& P_{i, t}=f\left(E_{i, t}, C_{i, t}\right) \\
& E_{i, t} \text { and } C_{i, t}=f\left(I_{i, t}, S, C B, P C, S B\right) \\
& S, C B, P C, S B=f(G) \\
& G=f\left(x_{j}\right)
\end{aligned}
$$

\section{B. Structuring Industry Businesses}

According to existing literature [25-27], industry evidence, and expert opinions, a structure for oil industry businesses is presented at three levels in Figure 2.

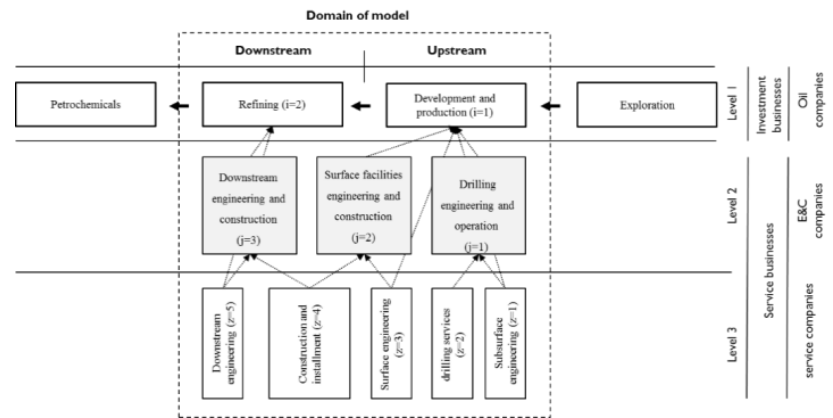

Fig. 2. Three-level structure for value chain of oil industry businesses

\section{Modeling Level-1 Businesses}

For modeling development and production business, a simplified model of Iran's new oil contracts, known as IPC, is considered. In this model, the contract period for a field is 20 years, during which the development of the field will take place over a period of 5 years, after which there will be three 5-year periods equal to 15 years of production. Capital expenditures related to the development period will be repaid by the National Oil Company during the operation period (with a delay of 5 years) including financial costs. Operating costs are repaid on an annual basis, and the oil company will receive a certain amount of remuneration (reward) per barrel of production. In refining business, we consider five years as construction (or acquisition) period as well, while having 25 years ( 5 periods) of operation. We assume that there is no competition to obtain the license for investment in these two businesses of level-1. Since this research seeks to model a business and not a project, we consider another type of costs as indirect costs of a business in the model. It includes non-project costs such as costs for administration or key personnel of the headquarters.

TABLE I. MODEL VARIABLES FOR LEVEL-1 BUSINESSES

\begin{tabular}{|c|c|}
\hline Description & Variable \\
\hline Investment in business i in period t & $\boldsymbol{C} \boldsymbol{X}_{\boldsymbol{i}, \boldsymbol{t}}$ \\
\hline Increase in oil production capacity in period t & $\boldsymbol{u}_{\boldsymbol{t}}$ \\
\hline Oil production in period t & $\boldsymbol{U}_{\boldsymbol{t}}$ \\
\hline Increase in refining capacity in period t & $\boldsymbol{q}_{\boldsymbol{t}}$ \\
\hline Production of refining products in period t & $\boldsymbol{Q}_{\boldsymbol{t}}$ \\
\hline Rewards of oil production (remuneration) in period t & $\boldsymbol{R}_{\boldsymbol{t}}$ \\
\hline Direct costs of refinery operation in period t & $\boldsymbol{O X}_{\boldsymbol{t}}$ \\
\hline Income from business i in period t & $\boldsymbol{E}_{\boldsymbol{i}, \boldsymbol{t}}$ \\
\hline Indirect business costs i & $\boldsymbol{I} \boldsymbol{C}_{\boldsymbol{i}, \boldsymbol{t}}$ \\
\hline Profit by business i in period t & $\boldsymbol{P}_{\boldsymbol{i}, \boldsymbol{t}}$ \\
\hline Future potential benefits from investment in business i & $\boldsymbol{P}_{\boldsymbol{i}}^{f}$ \\
\hline Economic value added from business i in period t & $\boldsymbol{E} \boldsymbol{V} \boldsymbol{A}_{\boldsymbol{i}, \boldsymbol{t}}$ \\
\hline
\end{tabular}

In development and production, if $c x$ dollars is needed to increase production capacity for a barrel per day, with $C B_{1}$ as the capabilities level of the company in this business (which is defined in the range of 0 to 1 and its average is the normal capability in the industry), we will have:

$$
u_{t}=\frac{\left(C B_{1}+.5\right) \cdot C X_{1, t}}{c x}
$$

The power relationship is used to estimate the amount of investment required to build a refinery. It is widely applied to estimate initial investment costs for a refinery based on investment and capacity of a reference refinery [28]. According to this equation, if $C_{0}$ is regarded as the amount of investment to build a sample refinery with an annual capacity of $Q_{0}$ while we have company's capability $\left(C B_{2}\right)$, then:

$$
q_{t}=\left(C B_{2}+.5\right) \cdot Q_{0} \cdot \sqrt[0.6]{\frac{C X_{2, t}}{C_{0}}}
$$

The production capacity added in each period will be achieved not in that period but in future periods. Therefore, the amount of oil produced and refined product in each period is:

$$
U_{t}=\sum_{i=t-3>0}^{t-1} u_{i}
$$




$$
Q_{t}=\sum_{i=t-5>0}^{t-1} q_{i}
$$

In the contracts described for development and production, the corporate's profits in each period are equivalent to $f$ dollars reward per barrel of oil production:

$$
R_{t}=(5 * 365) \cdot f \cdot U_{t}
$$

In refining business, income is equal to the sales of refined products. If $p$ is the weighted average price of the corporate's refined products, by assuming 330 days of operation annually, we have:

$$
E_{2, t}=\left(5^{*} 330\right) Q_{t} \cdot p_{t}^{o}
$$

In development and production, the investment and the operating costs are both reimbursed by the National Iranian Oil Company, therefore, they are eliminated from the model calculations. In the refining business, the operating costs, which mainly include cost of feed, fuel, catalysts, etc. are directly related to the amount of refined products produced per period. Therefore, if we assume that the production of a barrel of petroleum products costs $o x$ dollars, operation cost in each period can be calculated considering the level of corporate's capability in refining business:

$$
O X_{2, t}=\frac{(5 * 330) o x . Q_{t}}{\left(C B_{2}+.5\right)}
$$

Meanwhile, indirect costs are affected by both production/operation and development of fields or new refineries. Therefore, they could be considered as a function of income or profits in each period ( $a_{i}$ dollar per barrel), the volume of investments in development $\left(b_{i}\right.$ dollars per investment dollar), and fixed costs of the business $\left(c_{i}\right)$.

$$
\begin{aligned}
& I C_{1, t}=\frac{x_{1}}{\left(C B_{1}+.5\right)}\left(a_{1} R_{t}+b_{1} C X_{1, t}+c_{1}\right) \\
& I C_{2, t}=\frac{x_{2}}{\left(C B_{2}+.5\right)}\left(a_{2} E_{2, t}+b_{2} C X_{2, t}+c_{2}\right)
\end{aligned}
$$

In these equations, $c_{i}$ represents the costs involved in having an operating business, regardless of contracts and projects such as cost of key personnel, buildings, etc. Now we can calculate the business profits of development and production in each period:

$$
\begin{aligned}
& I C_{1, t}=\frac{x_{1}}{\left(C B_{1}+.5\right)}\left(a_{1} R_{t}+b_{1} C X_{1, t}+c_{1}\right) \\
& P_{2, t}=E_{t}-O X_{2, t}-I C_{2, t}
\end{aligned}
$$

Therefore, the economic value added is:

$$
E V A_{i, t}=P_{i, t}-W A C C_{t} \cdot C X_{i, t}
$$

In addition, it should be noted that a part of investments in the 20-year period of the model, leads to future production in years after the problem period. Hence, at the end of the 20th year, potential future profits have been generated in addition to the profits received. If the average profitability per production over the 20 years is calculated and called $p_{i}$, we assume that profitability for production in future periods will continue according to such average. By discounting future profits with the rate of $W A C C_{t}$, we will have:

$$
\begin{aligned}
& \bar{p}_{1}=\frac{\sum_{t=1}^{4} P_{1, t}}{\sum_{t=1}^{4} U_{t}} \\
& \bar{p}_{2}=\frac{\sum_{t=1}^{4} P_{2, t}}{\sum_{t=1}^{4} Q_{t}} \\
& P_{1}^{f}=\sum_{t=5}^{7} \frac{\bar{p}_{1} \cdot U_{t}}{\left(1+W A C C_{t}\right)^{t}} \\
& P_{2}^{f}=\sum_{t=5}^{9} \frac{\bar{p}_{2} \cdot Q_{t}}{\left(1+W A C C_{t}\right)^{t}}
\end{aligned}
$$

\section{Modeling Level-2 and Level-3 Businesses}

While investment is a key function in level-1 businesses, in level-2 and level-3 businesses that are contracting and service businesses, investment is not essential. In these businesses, the cash flow depends on the company's contracts and invoices. Nevertheless, drilling services $(k=2)$ and construction and installation $(k=4)$ are "equipment-based". Therefore, investing in machines and equipment is required in mentioned businesses. The variables for each business in level-2 $(j=1-3)$ and level-3 $(k=1-5)$ are defined in Table II.

TABLE II. MODEL VARIABLES FOR LEVEL-2 AND LEVEL-3 BUSINESSES

\begin{tabular}{|c|c|c|}
\hline \multirow{2}{*}{ Description } & \multicolumn{2}{|c|}{ Variable } \\
\cline { 2 - 3 } & Level-2 & Level-3 \\
\hline Investment in period $t$ & - & $\boldsymbol{K}_{\boldsymbol{k}, \boldsymbol{t}}^{\prime \prime}$ \\
\hline Income in period $t$ & $\boldsymbol{E}_{\boldsymbol{j}, \boldsymbol{t}}^{\prime}$ & $\boldsymbol{E}_{\boldsymbol{k}, \boldsymbol{t}}^{\prime \prime}$ \\
\hline Direct costs in period $t$ & $\boldsymbol{I} \boldsymbol{C}_{j, \boldsymbol{t}}^{\prime}$ & $\boldsymbol{I}_{\boldsymbol{k}, \boldsymbol{t}}^{\prime \prime}$ \\
\hline Indirect costs in period $t$ & $\boldsymbol{D} \boldsymbol{C}_{\boldsymbol{j}, \boldsymbol{t}}^{\prime}$ & $\boldsymbol{D} \boldsymbol{C}_{\boldsymbol{k}, \boldsymbol{t}}^{\prime \prime}$ \\
\hline Profit in period $t$ & $\boldsymbol{P}_{\boldsymbol{i}, \boldsymbol{t}}$ & $\boldsymbol{P}_{\boldsymbol{i}, \boldsymbol{t}}$ \\
\hline Economic value added in period $t$ & $\boldsymbol{E} \boldsymbol{\boldsymbol { A } _ { \boldsymbol { i } , \boldsymbol { t } }}$ & $\boldsymbol{E} \boldsymbol{V} \boldsymbol{A}_{\boldsymbol{i}, \boldsymbol{t}}$ \\
\hline
\end{tabular}

If we show the total market value of business $j$ in period $t$ as $M_{j, t}^{\prime}$ and the total market value of business $k$ in period $\mathrm{t}$ as $M_{j, t}^{\prime \prime}$ , we will have:

$$
\begin{aligned}
& E_{j, t}^{\prime}=y_{j} M_{j, t}^{\prime} S_{j}^{\prime}\left(C B_{j}^{\prime}+.5\right) \\
& E_{k, t}^{\prime \prime}=z_{k} M_{k, t}^{\prime \prime} S_{k}^{\prime \prime}\left(C B_{k}^{\prime \prime}+.5\right)
\end{aligned}
$$

where $S_{j}^{\prime}$ and $S_{j}^{\prime \prime}$ represent the corporate's potential market share (percentages) in business $j$ and $k$, which is affected by the market conditions, the number of competitors and the intensity of the competition. Since service contracts are often awarded competitively through tenders, all this potential market share is not actualized. Indeed, the corporate's capability in a business $\left(C B^{\prime}{ }_{k}\right.$ and $\left.C B^{\prime \prime}{ }_{j}\right)$ is a determinant factor in this regard. Therefore, in the above relation, $S_{j}^{\prime}$ and $S^{\prime \prime}{ }_{k}$ indicate the effect 
of external factors outside the control of the company. $C B_{j}^{\prime}$ and $C B^{\prime \prime}{ }_{k}$ represent the effects of internal factors such as bid prices on tenders, capabilities, competitive advantage, and so on. We also assume that each business has a specific profit margin $\left(m_{j}^{\prime}\right.$ and $m^{\prime \prime}{ }_{k}$ ), which is the remainder of the contract after deducting direct costs. Thus, we have the direct costs:

$$
\begin{aligned}
& D C_{j, t}^{\prime}=\frac{\left(1-m_{j}^{\prime}\right)}{\left(C B_{j}^{\prime}+.5\right)} E_{j, t}^{\prime} \\
& D C_{k, t}^{\prime \prime}=\frac{\left(1-m_{k}^{\prime \prime}\right)}{\left(C B_{k}^{\prime \prime}+.5\right)} E_{k, t}^{\prime \prime}
\end{aligned}
$$

Indirect costs of a business are a function of the amount of contracts in hand ( $a^{\prime}$ and $a^{\prime \prime}$ dollars per each dollar of contract value) as an indicator of current workload of the corporate. In case of equipment-based businesses, it is also a function of inhand equipment $\left(b^{\prime \prime}\right.$ dollars per each dollar of investment in equipment) as an indicator of business size and related maintenance costs:

$$
\begin{aligned}
& I C_{\mathrm{j}, t}^{\prime}=\frac{y_{j}}{\left(C B_{j}^{\prime}+.5\right)}\left(a^{\prime} E_{j, t}^{\prime}+c^{\prime}\right) \\
& I C_{\mathrm{k}, t}^{\prime \prime}=\frac{z_{k}}{\left(C B_{k}^{\prime \prime}+.5\right)}\left(a^{\prime \prime} E_{\mathrm{k}, t}^{\prime \prime}+b^{\prime \prime} K_{\mathrm{k}, t}^{\prime \prime}+c^{\prime \prime}\right)
\end{aligned}
$$

where $c^{\prime}$ and $c^{\prime \prime}$ indicate the fixed costs that occur regardless of having a contract during a period only because of the presence of that business, such as the cost of key personnel and staff. Based on the above, the profit could be calculated as:

$$
\begin{aligned}
& P_{j, t}^{\prime}=E_{j, t}^{\prime}-D C_{j, t}^{\prime}-I C_{j, t}^{\prime} \\
& P_{k, t}^{\prime \prime}=E_{k, t}^{\prime \prime}-D C_{k, t}^{\prime \prime}-I C_{k, t}^{\prime \prime}
\end{aligned}
$$

and for economic value added:

$$
\begin{aligned}
& E V A_{j, t}^{\prime}=P_{j, t}^{\prime} \\
& E V A_{k, t}^{\prime \prime}=P_{k, t}^{\prime \prime}-W A C C_{t} \cdot K_{k, t}^{\prime \prime}
\end{aligned}
$$

\section{E. Synergy of Businesses}

So far, the model has been developed by considering businesses independent. However, the link and synergy between them is a decisive factor in portfolio design. In other words, adopting a systematic look at the portfolio of businesses suggests that being or not being in a business can affect parameters of another business. If $c b_{i}, c b_{j}^{\prime}$ and $c b^{\prime \prime}{ }_{k}$ are independent capability parameters in each business of level 1, 2 and 3, adopting a system approach means that being in an business can lead to an increase or decrease in the capability level of another business. If $C B_{i}, C B_{j}^{\prime}$ and $C B^{\prime \prime}{ }_{k}$ are respectively the variables relating to the corporate's capabilities in each three level businesses, we define: $\mu_{m, p, n, q}^{c b} \in[-1,1]$ as the capability impact factor of business $m$ from level $p$ on business $n$ from level $q$. Now, the effect of all other businesses on business $n$ of the level $q$ could be shown by the "capability synergy function" for business $n$ of level $q$ which is defined as:

$$
G_{n, q}^{C b}=\frac{\sum_{i=1}^{2} x_{i} \cdot \mu_{i, 1, n, q}^{C b}+\sum_{j=1}^{3} y_{j} \cdot \mu_{j, 2, n, q}^{C b}+\sum_{k=1}^{5} z_{k} \cdot \mu_{k, 3, n, q}^{C b}}{\sum_{i=1}^{3} x_{i}+\sum_{j=1}^{3} y_{j}+\sum_{k=1}^{5} z_{k}}
$$

Therefore, we will have:

$$
\begin{aligned}
& C B_{i}=c b_{i} \cdot\left(1+G_{i, 1}^{C b}\right) \\
& C B_{j}^{\prime}=c b_{j}^{\prime} \cdot\left(1+G_{j, 2}^{C b}\right) \\
& C B_{k}^{\prime \prime}=c b_{k}^{\prime \prime} \cdot\left(1+G_{k, 3}^{C b}\right)
\end{aligned}
$$

Having the above mentioned function, corporate's capability level in a business that was considered as an independent parameter is now modified by considering the synergistic effect of other businesses in the portfolio. In the same way, if the parameters $s_{i}, s_{j}^{\prime}$ and $s^{\prime \prime}{ }_{k}$ are the potential market share in each business of level 1,2 and 3, adopting a system approach and considering the presence in other businesses can lead to an increase or decrease in this share and a change in the market position. If $S_{i}, S_{j}^{\prime}$, and $S^{\prime \prime}{ }_{k}$ are respectively the variables indicating potential market share in each of the level 1, 2 and 3 businesses, by considering the link between businesses in a portfolio, we define: $\mu_{m, p, n, q}^{S} \in[-1,1]$ as the market impact factor of business $m$ from the level $p$ on business $n$ from level $q$. Meanwhile, we can define the "market synergy function" for business $n$ from level $q$ as:

$$
\begin{aligned}
& G_{n, q}^{S}=\frac{\sum_{i=1}^{2} x_{i} \cdot \mu_{i, 1, n, q}^{S}+\sum_{j=1}^{3} y_{j} \cdot \mu_{j, 2, n, q}^{S}+\sum_{k=1}^{5} z_{k} \cdot \mu_{k, 3, n, q}^{S}}{\sum_{i=1}^{3} x_{i}+\sum_{j=1}^{3} y_{j}+\sum_{k=1}^{5} z_{k}} \\
& S_{i}=S_{i} \cdot\left(1+G_{i, 1}^{S}\right) \\
& S_{j}^{\prime}=S_{j}^{\prime} \cdot\left(1+G_{j, 2}^{S}\right) \\
& S_{k}^{\prime \prime}=S_{k}^{\prime \prime} \cdot\left(1+G_{k, 3}^{S}\right)
\end{aligned}
$$

\section{F. Parenting Cost and Sharing Benefits}

By establishing a portfolio of businesses, new overhead costs, called "parenting costs", are generated. Since these costs have a direct relation to size of the corporate and its operation, we can estimate them as a percentage $(h)$ of the total income:

$$
P C_{t}=h \cdot\left(\sum_{i=1}^{2} E_{i, t}+\sum_{j=1}^{3} E_{j, t}^{\prime}+\sum_{k=1}^{5} E_{k, t}^{\prime \prime}\right)
$$

Moreover, given that these costs are mainly spent on strategic management, financial management, audits and controls, etc., we distribute it equally among active businesses:

$$
\begin{aligned}
& P C_{i, t}=\frac{x_{i} \cdot P C_{t}}{\sum_{i=1}^{3} x_{i}+\sum_{j=1}^{3} y_{j}+\sum_{k=1}^{5} z_{k}} \\
& P C_{j, t}^{\prime}=\frac{y_{j} \cdot P C_{t}}{\sum_{i=1}^{3} x_{i}+\sum_{j=1}^{3} y_{j}+\sum_{k=1}^{5} z_{k}}
\end{aligned}
$$




$$
P C_{k, t}^{\prime \prime}=\frac{z_{k} \cdot P C_{t}}{\sum_{i=1}^{3} x_{i}+\sum_{j=1}^{3} y_{j}+\sum_{k=1}^{5} z_{k}}
$$

Conversely, by forming a business portfolio, it is possible to share costs among some businesses. For this purpose, we define $\mu_{m, p, n, q}^{S b} \in[-1,1]$ as the sharing impact factor between business $m$ at level $p$ with business $n$ at level $q$. Now, we define the "sharing benefit function" for business $n$ from level $q$ as:

$$
G_{n, q}^{S B}=\frac{\sum_{i=1}^{2} x_{i} \cdot \mu_{i, 1, n, q}^{S b}+\sum_{j=1}^{3} y_{j} \cdot \mu_{j, 2, n, q}^{S b}+\sum_{k=1}^{5} z_{k} \cdot \mu_{k, 3, n, q}^{S b}}{\sum_{i=1}^{3} x_{i}+\sum_{j=1}^{3} y_{j}+\sum_{k=1}^{5} z_{k}}
$$

To apply the benefits of cost sharing into the model, we assume that the cost-sharing function decreases the indirect costs of each business in each period. Since this cost sharing cannot be unlimited and must include a part of indirect costs, we restrict it to a $\theta$ percentage of indirect costs. Therefore, we will have:

$$
\begin{aligned}
& S B_{i, t}=\operatorname{Min}\left(G_{i, 1}^{S b}, \theta\right) \cdot I C_{i, t} \\
& S B_{j, t}^{\prime}=\operatorname{Min}\left(G_{j, 2}^{S b}, \theta\right) \cdot I C_{j, t}^{\prime} \\
& S B_{k, t}^{\prime \prime}=\operatorname{Min}\left(G_{k, 3}^{S b}, \theta\right) \cdot I C_{i, k}^{\prime \prime}
\end{aligned}
$$

By considering parenting costs and cost sharing benefits, business profits should be modified as follows:

$$
\begin{aligned}
& P_{1, t}=R_{t}-I C_{1, t}+S B_{1, t}-P C_{1, t} \\
& P_{2, t}=E_{2, t}-O X_{2, t}-I C_{2, t}+S B_{2, t}-P C_{2, t} \\
& P_{j, t}^{\prime}=E_{j, t}^{\prime}-D C_{j, t}^{\prime}-I C_{j, t}^{\prime}+S B_{j, t}^{\prime}-P C_{j, t}^{\prime} \\
& P_{k, t}^{\prime \prime}=E_{k, t}^{\prime \prime}-D C_{k, t}^{\prime \prime}-I C_{k, t}^{\prime \prime}+S B_{k, t}^{\prime \prime}-P C_{k, t}^{\prime \prime}
\end{aligned}
$$

\section{G. Objective Function} is:

According to the conceptual model, the objective function

$$
\begin{aligned}
& \operatorname{Max} Z_{1}=\left[\sum_{t=1}^{4} \frac{1}{\left(1+W A C C_{t}\right)^{t}}\left(\sum_{i=1}^{2} E V A_{i, t}+\sum_{j=1}^{3} E V A_{j, t}^{\prime}+\sum_{k=1}^{5} E V A_{k, t}^{\prime \prime}\right)\right] \\
&+P_{1}^{f}+P_{2}^{f} \\
& \operatorname{Max} Z_{2}==\sum_{t=2}^{4}\left(\sum_{i=1}^{2}\left(E_{i, t+1}-E_{i, t}\right)+\sum_{j=1}^{3}\left(E_{j, t+1}^{\prime}-E_{j, t}^{\prime}\right)+\sum_{k=1}^{5}\left(E_{k, t+1}^{\prime}-E_{k, t}^{\prime \prime}\right)\right) \\
& \operatorname{Min} Z_{3}=\sum_{t=1}^{4} \sqrt{\left[\left(\sum_{i=1}^{2} P_{i, t}+\sum_{j=1}^{3} P_{j, t}^{\prime}+\sum_{k=1}^{5} P_{k, t}^{\prime \prime}\right)-\bar{P}\right]^{2}}
\end{aligned}
$$

\section{H. Constraints}

The first constraint is the limitation of resources for investment. If the total capital available for the period $\mathrm{t}$ is $C_{t}$, then we have:

$$
C X_{1, t}+C X_{2, t}+K_{2, t}^{\prime \prime}+K_{4, t}^{\prime \prime} \leq C_{t}
$$

Moreover, minimum required investment for level-1 and equipment-based businesses in level-3 can be defined as:

$$
\begin{gathered}
C X_{i, t} \leq C_{i}(\min ) \\
K_{j, t}^{\prime \prime} \leq K_{j}^{\prime \prime}(\text { min })
\end{gathered}
$$

In equipment-based businesses $(k=2,4)$, we consider that reinvestment in each period should be at least equal to the rate of depreciation in that business $\left(\tau_{k}\right)$ :

$$
\frac{K_{k, t+1}^{\prime \prime}}{K_{k, t}^{\prime \prime}} \geq \tau_{k}
$$

Although size, the potential contribution of the market and capabilities are still decisive for equipment-based businesses ("drilling" and "construction and installation"), available equipment is also a limiting factor because the services provided by these businesses are depended on their equipment and machinery. Hence, we apply the following limitation in the model for these businesses $(k=2,4)$ :

$$
E_{k, t}^{\prime \prime} \leq 5 z_{k} \eta_{k} \sum_{i=1}^{t} K_{k, i}^{\prime \prime}
$$

Where $\eta_{k}$ is the "revenue generating ratio" which is defined for each equipment-based business $(k=2,4)$ as the maximum amount of annual revenue that could be generated per unit of investment in equipment and machinery. Meanwhile, investing in a business is subject to the presence in it. So:

$$
\begin{aligned}
& \left(x_{i}-1\right) C X_{i, t}=0 \\
& \left(z_{k}-1\right) K_{k, t}^{\prime \prime}=0
\end{aligned}
$$

Finally:

$$
x_{i}, y_{j}=0,1
$$

Other variables $\geq 0$

\section{SOLVING THE MODEL AND RESULTS}

To solve the model, three companies in the Iranian oil and gas industry were studied (Cases 1-3). Each of these companies represents a type of corporate that has the competitive advantage and capability mainly in level 1,2 and 3 of the hierarchy presented in Figure 2 respectively. In order to analyze the results better, the model is solved in two modes:

- System Inter-Relationship mode (SI-mode): In this case, the links among businesses in the forms of market synergy, capabilities synergy, parenting costs and sharing benefits are included in the model.

- Elements Independency mode (EI-mode): In this case, the relationships between businesses and their impact on each other are removed from the model. Hence, all variables and parameters are considered independent of other existing businesses in the portfolio. To solve in the EI approach, the values of $\mu_{m, p, n, q}^{c b}, \mu_{m, p, n, q}^{S}, h$, and $\theta$ are considered equal to zero. 
Fuzzy Delphi method has been used to determine the parameters of synergy, sharing benefits and capability level of case studies (Tables IV-VI). The linguistic variables used for this purpose are the seven-point scale presented in Table III [29]. Defuzzification of values is done by center of gravity (COG) method [30]. Other parameters used to solve the model are presented in Tables VII and VIII.
TABLE III. LINGUISTIC VARIABLES USED IN THE RESEARCH

\begin{tabular}{|c|c|}
\hline Linguistic variables & Fuzzy number \\
\hline Very high $(\mathrm{VH})$ & $(0.9,1,1)$ \\
\hline High $(\mathrm{H})$ & $(0.7,0.9,1)$ \\
\hline Medium high $(\mathrm{MH})$ & $(0.5,0.7,1)$ \\
\hline Medium $(\mathrm{M})$ & $(0.3,0.5,0.7)$ \\
\hline Medium low (ML) & $(0.1,03,05)$ \\
\hline Low (L) & $(0,0.1,0.3)$ \\
\hline Very low (VL) & $(0,0,0.1)$ \\
\hline
\end{tabular}

TABLE IV. MARKET IMPACT FACTOR $\left(\mu_{m, p, n, q}^{s}\right)$

\begin{tabular}{|c|c|c|c|c|c|c|c|c|c|c|c|c|}
\hline & & \multicolumn{2}{|c|}{$q=1$} & \multicolumn{3}{|c|}{$q=2$} & \multicolumn{5}{|c|}{$q=3$} & \multirow{2}{*}{ Tota } \\
\hline & & $n=1$ & $n=2$ & $n=1$ & $n=2$ & $n=3$ & $n=1$ & $n=2$ & $n=3$ & $n=4$ & $n=5$ & \\
\hline \multirow[b]{2}{*}{$p=1$} & $m=1$ & 0.000 & 0.190 & 0.430 & 0.430 & 0.033 & 0.550 & 0.430 & 0.550 & 0.367 & 0.033 & 3.013 \\
\hline & $m=2$ & 0.240 & 0.000 & 0.033 & 0.033 & 0.430 & 0.033 & 0.033 & 0.033 & 0.367 & 0.550 & 1.752 \\
\hline \multirow{3}{*}{$p=2$} & $m=1$ & 0.097 & 0.033 & 0.000 & 0.240 & 0.033 & 0.430 & 0.430 & 0.097 & 0.033 & 0.033 & 1.426 \\
\hline & $m=2$ & 0.097 & 0.033 & 0.240 & 0.000 & 0.033 & 0.097 & 0.033 & 0.430 & 0.367 & 0.033 & 1.363 \\
\hline & $m=3$ & 0.033 & 0.097 & 0.033 & 0.190 & 0.000 & 0.033 & 0.033 & 0.097 & 0.367 & 0.430 & 1.313 \\
\hline \multirow{5}{*}{$p=3$} & $m=1$ & 0.097 & 0.033 & 0.240 & 0.097 & 0.033 & 0.000 & 0.190 & 0.190 & 0.033 & 0.033 & 0.946 \\
\hline & $m=2$ & 0.033 & 0.033 & 0.240 & 0.097 & 0.033 & 0.190 & 0.000 & 0.033 & 0.033 & 0.033 & 0.725 \\
\hline & $m=3$ & 0.067 & 0.033 & 0.097 & 0.240 & 0.033 & 0.190 & 0.033 & 0.000 & 0.240 & 0.033 & 0.966 \\
\hline & $m=4$ & 0.033 & 0.033 & 0.033 & 0.097 & 0.097 & 0.033 & 0.033 & 0.240 & 0.000 & 0.240 & 0.839 \\
\hline & $m=5$ & 0.033 & 0.097 & 0.033 & 0.097 & 0.240 & 0.033 & 0.033 & 0.033 & 0.240 & 0.000 & 0.839 \\
\hline \multicolumn{2}{|c|}{ Total } & 0.73 & 0.582 & 1.379 & 1.521 & 0.965 & 1.589 & 1.248 & 1.703 & 2.047 & 1.418 & \\
\hline
\end{tabular}

TABLE V. CAPABILITY IMPACT FACTOR $\left(\mu_{m, p, n, q}^{C b}\right)$

\begin{tabular}{|c|c|c|c|c|c|c|c|c|c|c|c|c|}
\hline & & \multicolumn{2}{|c|}{$q=1$} & \multicolumn{3}{|c|}{$q=2$} & \multicolumn{5}{|c|}{$q=3$} & \multirow{2}{*}{ Total } \\
\hline & & $n=1$ & $n=2$ & $n=1$ & $n=2$ & $n=3$ & $n=1$ & $n=2$ & $n=3$ & $n=4$ & $n=5$ & \\
\hline \multirow{2}{*}{$p=1$} & $m=1$ & 0.000 & 0.217 & 0.190 & 0.083 & 0.033 & 0.083 & 0.083 & 0.083 & 0.067 & 0.033 & 0.872 \\
\hline & $m=2$ & 0.217 & 0.000 & 0.033 & 0.083 & 0.217 & 0.033 & 0.033 & 0.033 & 0.083 & 0.083 & 0.815 \\
\hline \multirow{3}{*}{$p=2$} & $m=1$ & 0.217 & 0.033 & 0.000 & 0.067 & 0.033 & 0.083 & 0.190 & 0.067 & 0.033 & 0.033 & 0.756 \\
\hline & $m=2$ & 0.190 & 0.033 & 0.067 & 0.000 & 0.217 & 0.033 & 0.033 & 0.083 & 0.190 & 0.083 & 0.929 \\
\hline & $m=3$ & 0.033 & 0.217 & 0.033 & 0.217 & 0.000 & 0.033 & 0.033 & 0.083 & 0.190 & 0.083 & 0.922 \\
\hline \multirow{5}{*}{$p=3$} & $m=1$ & 0.430 & 0.033 & 0.273 & 0.190 & 0.033 & 0.000 & 0.217 & 0.190 & 0.033 & 0.033 & 1.432 \\
\hline & $m=2$ & 0.067 & 0.033 & 0.217 & 0.033 & 0.033 & 0.067 & 0.000 & 0.033 & 0.033 & 0.033 & 0.549 \\
\hline & $m=3$ & 0.217 & 0.083 & 0.083 & 0.273 & 0.067 & 0.190 & 0.033 & 0.000 & 0.190 & 0.190 & 1.326 \\
\hline & $m=4$ & 0.033 & 0.067 & 0.033 & 0.258 & 0.258 & 0.033 & 0.033 & 0.067 & 0.000 & 0.067 & 0.849 \\
\hline & $m=5$ & 0.033 & 0.430 & 0.033 & 0.083 & 0.273 & 0.033 & 0.033 & 0.217 & 0.190 & 0.000 & 1.325 \\
\hline \multicolumn{2}{|c|}{ Total } & 1.437 & 1.146 & 0.962 & 1.287 & 1.164 & 0.588 & 0.688 & 0.856 & 1.009 & 0.638 & \\
\hline
\end{tabular}

TABLE VI. SHARING IMPACT FACTOR $\left(\mu_{m, p, n, q}^{S b}\right)$

\begin{tabular}{|c|c|c|c|c|c|c|c|c|c|c|c|c|}
\hline & & \multicolumn{2}{|c|}{$q=1$} & \multicolumn{3}{|c|}{$q=2$} & \multicolumn{5}{|c|}{$q=3$} & \multirow{2}{*}{ Total } \\
\hline & & $n=1$ & $n=2$ & $n=1$ & $n=1$ & $n=2$ & $n=1$ & $n=1$ & $n=2$ & $n=1$ & $n=1$ & \\
\hline \multirow{2}{*}{$p=1$} & $m=1$ & 0.000 & 0.387 & 0.175 & 0.175 & 0.033 & 0.175 & 0.058 & 0.175 & 0.033 & 0.058 & 1.269 \\
\hline & $m=2$ & 0.387 & 0.000 & 0.033 & 0.033 & 0.175 & 0.033 & 0.033 & 0.083 & 0.083 & 0.175 & 1.035 \\
\hline \multirow{3}{*}{$p=2$} & $m=1$ & 0.175 & 0.033 & 0.000 & 0.175 & 0.058 & 0.175 & 0.217 & 0.083 & 0.058 & 0.058 & 1.032 \\
\hline & $m=2$ & 0.175 & 0.033 & 0.175 & 0.000 & 0.387 & 0.083 & 0.058 & 0.083 & 0.217 & 0.083 & 1.294 \\
\hline & $m=3$ & 0.033 & 0.175 & 0.058 & 0.387 & 0.000 & 0.083 & 0.058 & 0.083 & 0.217 & 0.083 & 1.177 \\
\hline \multirow{5}{*}{$p=3$} & $m=1$ & 0.175 & 0.033 & 0.175 & 0.083 & 0.083 & 0.000 & 0.083 & 0.258 & 0.033 & 0.058 & 0.981 \\
\hline & $m=2$ & 0.058 & 0.033 & 0.217 & 0.058 & 0.058 & 0.083 & 0.000 & 0.058 & 0.033 & 0.033 & 0.631 \\
\hline & $m=3$ & 0.175 & 0.083 & 0.083 & 0.083 & 0.083 & 0.258 & 0.058 & 0.000 & 0.083 & 0.387 & 1.293 \\
\hline & $m=4$ & 0.033 & 0.083 & 0.058 & 0.217 & 0.217 & 0.033 & 0.033 & 0.083 & 0.000 & 0.083 & 0.840 \\
\hline & $m=5$ & 0.058 & 0.175 & 0.058 & 0.083 & 0.083 & 0.058 & 0.033 & 0.387 & 0.083 & 0.000 & 1.018 \\
\hline \multicolumn{2}{|c|}{ Total } & 1.269 & 1.035 & 1.032 & 1.294 & 1.177 & 0.981 & 0.631 & 1.293 & 0.840 & 1.018 & \\
\hline
\end{tabular}

TABLE VII. CAPABILITY LEVEL OF CASES IN EACH BUSINESS

\begin{tabular}{|c|c|c|c|c|c|c|c|c|c|c|}
\hline Parameter & $\boldsymbol{c} \boldsymbol{b}_{\mathbf{1}}$ & $\boldsymbol{c} \boldsymbol{b}_{\mathbf{2}}$ & $\boldsymbol{c} \boldsymbol{b}_{\mathbf{1}}^{\prime}$ & $\boldsymbol{c} \boldsymbol{b}_{\mathbf{2}}^{\prime}$ & $\boldsymbol{c} \boldsymbol{b}_{\mathbf{3}}^{\prime}$ & $\boldsymbol{c} \boldsymbol{b}_{\mathbf{1}}^{\prime \prime}$ & $\boldsymbol{c} \boldsymbol{b}_{2}^{\prime \prime}$ & $\boldsymbol{c} \boldsymbol{b}_{3}^{\prime \prime}$ & $\boldsymbol{c} \boldsymbol{b}_{\mathbf{4}}^{\prime \prime}$ & $\boldsymbol{c} \boldsymbol{b}_{5}^{\prime \prime}$ \\
\hline Case 1 & 0.78 & 0.78 & 0.40 & 0.22 & 0.22 & 0.40 & 0.78 & 0.40 & 0.08 & 0.08 \\
\hline Case 2 & 0.40 & 0.22 & 0.78 & 0.92 & 0.92 & 0.78 & 0.08 & 0.92 & 0.08 & 0.92 \\
\hline Case 3 & 0.08 & 0.08 & 0.08 & 0.22 & 0.22 & 0.08 & 0.03 & 0.50 & 0.92 & 0.60 \\
\hline
\end{tabular}


TABLE VIII. MODEL PARAMETERS

\begin{tabular}{|c|c|c|c|c|c|c|c|}
\hline Parameter & Value & Parameter & Value & Parameter & Value & Parameter & Value \\
\hline$M_{1}^{\prime}$ & $32,000,000,000$ & $s_{4}^{\prime \prime}$ & 0.15 & $c x$ & 19,800 & $a_{1}$ & 0.0002 \\
\hline$M_{2}^{\prime}$ & $48,000,000,000$ & $s_{5}^{\prime \prime}$ & 0.10 & $o x$ & 56 & $a_{2}$ & 0.0002 \\
\hline$M_{3}^{\prime}$ & $25,000,000,000$ & WACC & 0.515 & $f$ & 4.8 & $a^{\prime}$ & 0.0020 \\
\hline$M_{1}^{\prime \prime}$ & $2,400,000,000$ & $C_{0}$ & $2,700,000,000$ & $C_{1}(\min )$ & $75,000,000$ & $a^{\prime \prime}$ & 0.0020 \\
\hline$M_{2}^{\prime \prime}$ & $12,800,000,000$ & $Q_{0}$ & 150,000 & $C_{2}(\min )$ & $150,000,000$ & $b_{1}$ & 0.0100 \\
\hline$M_{3}^{\prime \prime}$ & $2,400,000,000$ & $p_{t}$ & 65 & $K_{2}^{\prime \prime}(\min )$ & $6,000,000$ & $b_{2}$ & 0.0100 \\
\hline$M_{4}^{\prime \prime}$ & $25,550,000,000$ & $m_{1}^{\prime}$ & 0.07 & $K_{4}^{\prime \prime}(\min )$ & $5,500,000$ & $\boldsymbol{b}^{\prime \prime}$ & 0.0500 \\
\hline$M_{5}^{\prime \prime}$ & $1,250,000,000$ & $m_{2}^{\prime}$ & 0.08 & $\boldsymbol{C}_{\boldsymbol{t}}$-case1 & $250,000,000$ & $c_{1}$ & $4,950,000$ \\
\hline$s_{1}^{\prime}$ & 0.05 & $m_{3}^{\prime}$ & 0.08 & $\boldsymbol{C}_{\boldsymbol{t}}$-case 2 & $500,000,000$ & $c_{2}$ & $3,700,000$ \\
\hline$s_{2}^{\prime}$ & 0.05 & $m_{1}^{\prime \prime}$ & 0.19 & $C_{t}$-case 3 & $750,000,000$ & $c^{\prime}$ & $3,050,000$ \\
\hline$s_{3}^{\prime}$ & 0.10 & $m_{2}^{\prime \prime}$ & 0.41 & $\eta_{2}$ & 1.62 & $c^{\prime \prime}$ & $3,050,000$ \\
\hline$s_{1}^{\prime \prime}$ & 0.05 & $m_{3}^{\prime \prime}$ & 0.15 & $\eta_{4}$ & 1.12 & $h$ & 0.031 \\
\hline$s_{2}^{\prime \prime}$ & 0.05 & $\boldsymbol{m}_{4}^{\prime \prime}$ & 0.08 & $\tau_{2} / \tau_{4}$ & 0.5 & & \\
\hline$s_{3}^{\prime \prime}$ & 0.15 & $\boldsymbol{m}_{5}^{\prime \prime}$ & 0.15 & $\theta$ & 0.42 & & \\
\hline
\end{tabular}

The model we developed in this research is a highly complex one with a NP-Hard type that requires meta-heuristic methods to be solved. Therefore, we used non-dominant genetic algorithm as one of the most efficient and applicable multi-objective methods for obtaining appropriate answers [31]. Studies have shown that the improved version of this algorithm (NSGA-II) has better performance and less computational complexity than the previous versions, and provides better answers than the other presented algorithms [32]. Using this algorithm, the model is solved by Matlab software for each of the three cases in both EI and SI modes. The initial population is 200 , the number of generations is 100 , and the crossover rate is 0.8 . The chromosome defined for solving this model is a string of length 26,10 of which (to enter or not enter into a business) are Boolean variables. The rest (investment variables) are continuous variables. The objective function values for the answers set are shown in Figures 4 to 9 in the form of the Pareto front. Square polynomial fitting is used in order to gain a better picture of answers. In order to improve the results and reduce the impact of out-of-range answers, bi-square method has been used for robust fitting.

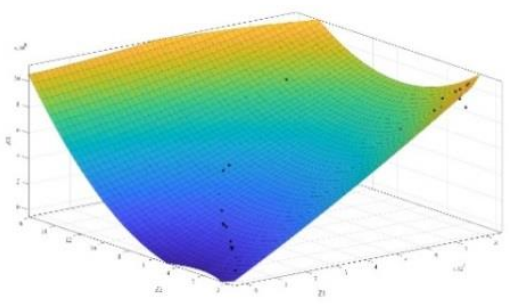

Fig. 3. Pareto front of objective functions for the first case - SI mode

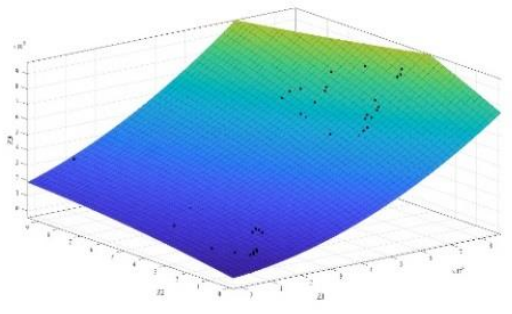

Fig. 4. Pareto front of objective functions for the first case - EI mode

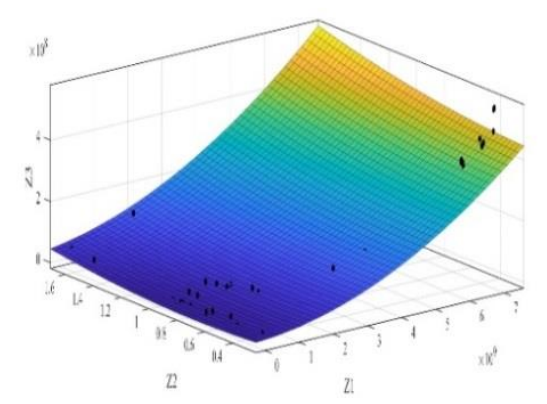

Fig. 5. Pareto front of objective functions for the second case - SI mode

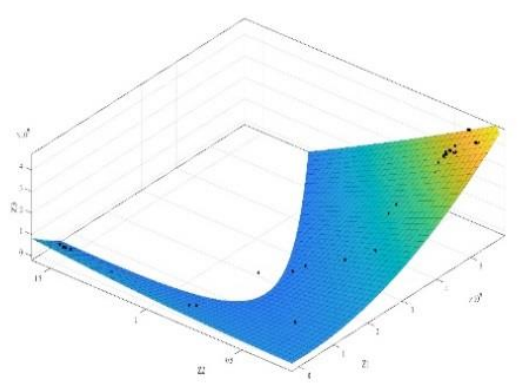

Fig. 6. Pareto front of objective functions for the second case - EI mode

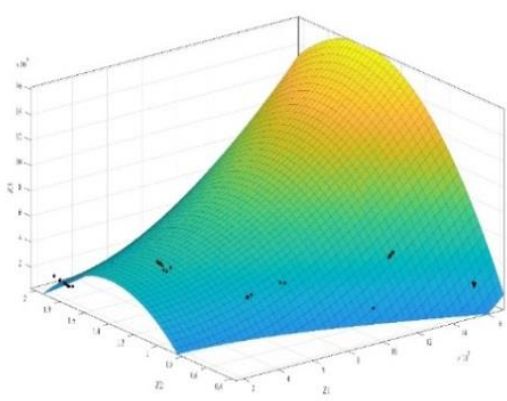

Fig. 7. Pareto front of objective functions for the third case - SI mode

In Figures 9-11, values of each objective function for the three cases are shown in both SI and EI modes. 


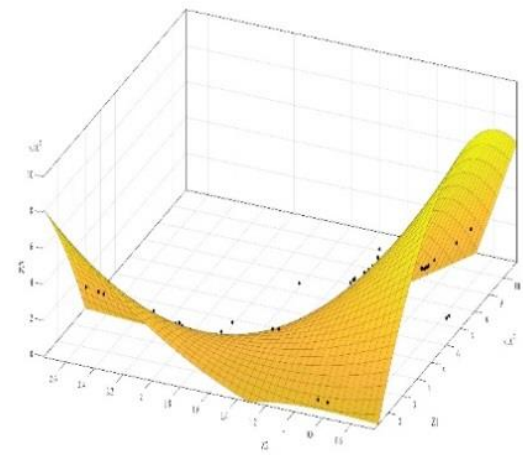

Fig. 8. Pareto front of objective functions for the third case - EI mode

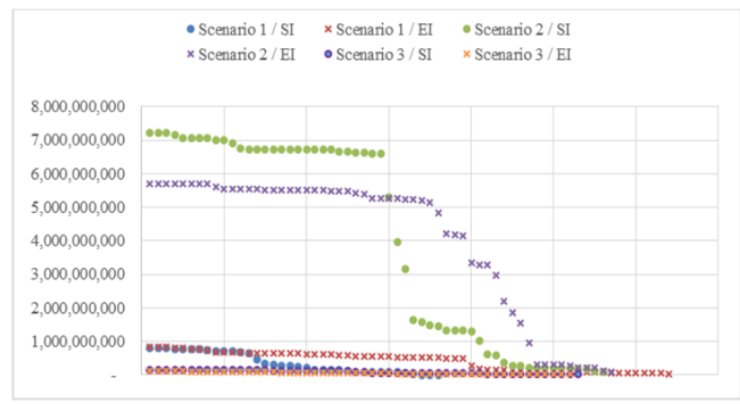

Fig. 9. Z1 for the three cases in SI and EI modes

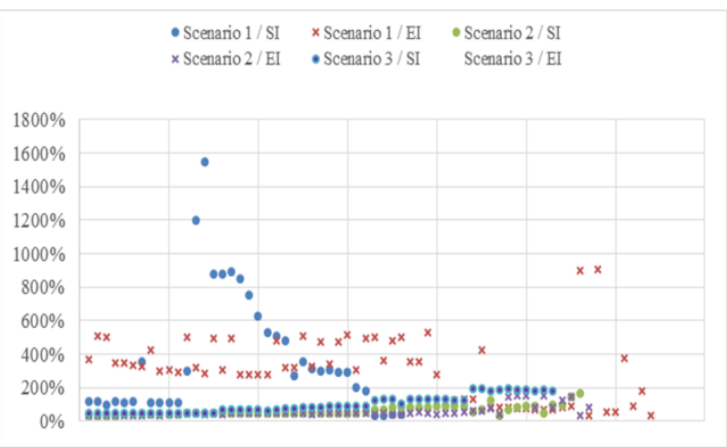

Fig. 10. Z2 for the three cases in SI and EI modes

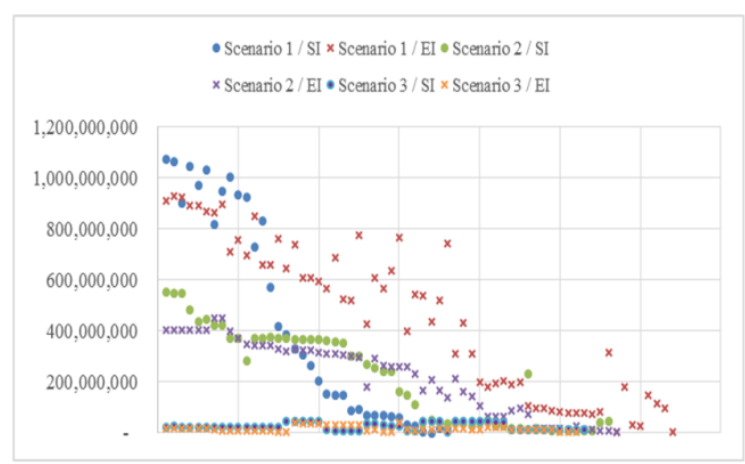

Fig. 11. Z3 for the three cases in SI and EI modes

In order to analyze the results obtained from decision variables, which represent entering or not entering into a business, the simple mean of values in each set of answers is calculated and presented separately for EI and SI modes in Figures 12 and 13.

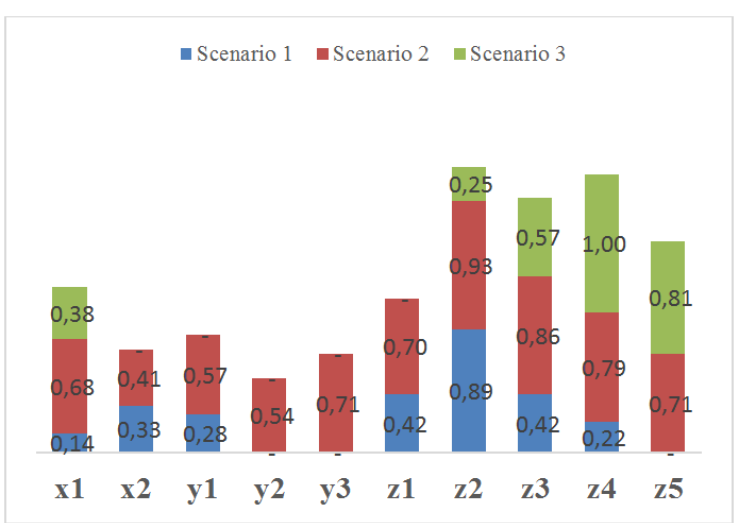

Fig. 12. Enter/not enter decision variable for the three cases - SI mode

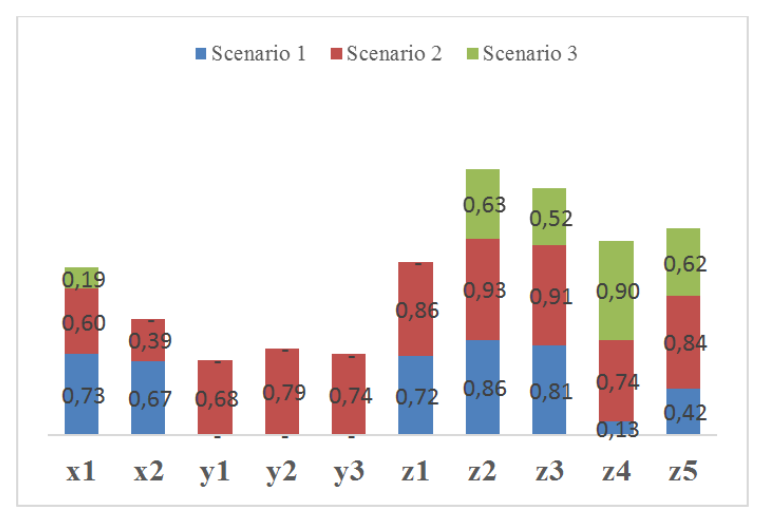

Fig. 13. Enter/not enter decision variable for the three cases - EI mode

\section{DISCUSSION AND CONCLUSION}

The main achievement of this research is the structuring and formulation of qualitative concepts of corporate strategy in form of a quantitative optimization model. It can support top management in the process of strategic decision making and designing business portfolio.

Analyzing synergistic impact factors shows that having engineering business in the portfolio has the greatest impact on improving the capability-level of other businesses. On the other hand, "Development and production" and "refining" businesses, followed by level-2 businesses, have the most positive impact on increasing the market share of other businesses. Such pattern shows that specialized and knowledge cores, which in the studied industry means engineering capabilities, have a significant role in enhancing the firm's capabilities even in upstream businesses. Hence, maintaining such businesses in vertical integration structure instead of outsourcing is feasible. For example, engaging in "subsurface engineering" $(k=1)$ that provides capabilities such as reservoir engineering and geology can affect the firm's capabilities in the "development and production" ( $i=1)$ and promote it. Moreover, entering into upstream businesses of the value chain can create internal markets for downstream businesses. In other words, in addition to direct benefits, investing in an upstream-level 
business can indirectly lead to new sources of income for the downstream businesses of a portfolio. Nevertheless, such benefits should be evaluated considering the costs incurred by entering the business, required investment and parenting costs needed for holding management. Legal barriers or strategic directions for assigning work to subsidiaries should also be considered in this regard.

Findings also show that the portfolio of the level-2 firm (case 2) performs better from the value adding point of view compared to level-1 companies (case 1). Although these results are obtained within our defined assumptions and constraints, it shows that presence in higher-level businesses does not necessarily mean more economic value added. Corporate managers should choose the optimum portfolio by considering internal factors such as the level of capabilities and external factors such as market potentials, as well as the interactions among businesses and their impact on each other. Besides, the optimal diversification-concentration strategies for each type of corporation could by proposed based on results:

- Type 1 (high level of competitive advantages and capabilities in level-1 businesses): The portfolio should be formed with a focus on level-1 capital-based businesses, including "development and production" and "refinement" along with outsourcing of level-2 E\&C operations. In order to play a better role as an employer, protecting corporate investments, benefit from internal markets and reduce risk, applying a "limited and relevant diversification" can be considered by entering into some level-3 businesses, especially engineering businesses.

- Type 2 (high level of competitive advantages and capabilities in level-2 businesses): The best strategy for these firms is "diversification"|. These firms would be better placed in all level-2 E\&C businesses, upstream and downstream. It is also better for these companies to include "engineering" in their business portfolio as it makes them more capable and with better performance in level-2 contracting tasks.

- Type 3 (high level of competitive advantage and capabilities in level-3 businesses): The appropriate strategy for these firms is "focus". These firms must refrain from engaging in field development and production contracts, investment, ownership of refineries and $\mathrm{E} \& \mathrm{C}$ businesses of Level-2. On the contrary, they should focus on those specialized engineering services in which they are more capable and competitive.

The findings also confirm that portfolio business performance (as a whole) is different from the total revenueexpenditure structure of individual business. Presence in a business can change the components of another business and, consequently, its revenue-expenditure structure. This effect does not necessarily mean that the values of the objective functions are improved when considering the whole portfolio, but could provide a more realistic picture of the portfolio's value-adding potential.

\section{FUTURE WORK SUGGESTIONS}

Given the wide range of stakeholders and decision criteria, further objectives could be included in prospective models, especially non-financial and non-economic ones such as environmental impacts or sustainable development, which have considerable importance in decision making for oil industry. Also, criteria such as employment creation and energy security that are of interest to national oil companies could be considered in future optimizations. Moreover, the dynamics of the relationship between variables over time periods can be applied in the model. For example, a continuous presence in a business can improve the market position in an upcoming period, and it will provide the firm with a competitive advantage compared to a newcomer. In addition, many of the variables used as deterministic variables can actually be defined as probabilistic variables, thus, the model becomes a probabilistic optimization model, in which the risk concept will be closer to real situations by covering issues beyond the fluctuations of profitability as it is considered in this research.

\section{REFERENCES}

[1] L. G. Franko, "The death of diversification? The focusing of the world's industrial corporates, 1980-2000", Business Horizons, Vol. 47, No. 4, pp. 41-50, 2004

[2] R. M. Grant, Contemporary Strategy Analysis: Text and Cases Edition, John Wiley \& Sons, 2016

[3] P. Ghemawat, "Competition and business strategy in historical perspective", Business History Review, Vol. 76, No. 1, pp. 37-74, 2002

[4] R. A. Proctor, J. S. Hassard, "Towards a New Model for Product Portfolio Analysis", Management Decision, Vol. 28, No. 3, 1990

[5] R. Mansini, W. Ogryczak, M. G. Speranza, "Twenty years of linear programming based portfolio optimization", European Journal of Operational Research, Vol. 234, No. 2, pp. 518-535, 2014

[6] G. Johnson, K. Scholes, R. Whittington, Exploring Corporate Strategy: Text \& Cases, Pearson Education, 2008

[7] M. E. Porter, "From competitive advantage to corporate strategy", in: Managing the Multibusiness Company: Strategic Issues for Diversified Groups, Cengage Learning EMEA, 1996

[8] J. R. Graham, M. L. Lemmon, J. G. Wolf, "Does corporate diversification destroy value?", The Journal of Finance, Vol. 57, No. 2, pp. 695-720, 2002

[9] O. A. Lamont, C. Polk, "Does diversification destroy value? Evidence from the industry shocks", Journal of Financial Economics, Vol. 63, No. 1, pp. 51-77, 2002

[10] J. D. Martin, A. Sayrak, "Corporate diversification and shareholder value: a survey of recent literature", Journal of Corporate Finance, Vol. 9, No. 1, pp. 37-57, 2003

[11] J. A. Doukas, O. B. Kan, "Does global diversification destroy corporate value?", Journal of International Business Studies, Vol. 37, No. 3, pp. 352-371, 2006

[12] R. P. Rumelt, "Diversification strategy and profitability", Strategic Management Journal, Vol. 3, No. 4, pp. 359-369, 1982

[13] S. A. Mansi, D. M. Reeb, "Corporate diversification: what gets discounted?", The Journal of Finance, Vol. 57, No. 5, pp. 2167-2183, 2002

[14] N. Berger, J. D. Cummins, M. A. Weiss, H. Zi, "Conglomeration versus strategic focus: Evidence from the insurance industry", Journal of Financial Intermediation, Vol. 9, No. 4, pp. 323-362, 2000

[15] S. P. Ferris, N. Sen, C. Y. Lim, G. H. Yeo, "Corporate focus versus diversification: the role of growth opportunities and cashflow", Journal of International Financial Markets, Institutions and Money, Vol. 12, No. 3 , pp. 231-252, 2002 
[16] S. B. Suslick, D. Schiozer, M. R. Rodriguez, "Uncertainty and risk analysis in petroleum exploration and production", Terræ, Vol. 6, No. 1, pp. 30-41, 2009

[17] D. P. Fichter, "Application of genetic algorithms in portfolio optimization for the oil and gas industry", SPE Annual Technical Conference and Exhibition, Dallas, Texas, USA, October 1-4, 2000

[18] M. Shakhsi-Niaei, S. H. Iranmanesh, S. A. Torabi, "A review of mathematical optimization applications in oil-and-gas upstream \& midstream management", International Journal of Energy and Statistics, Vol. 1, No. 2, pp. 143-154, 2013

[19] S. V. De Barros Bruno, C. Sagastizabal, "Optimization of real asset portfolio using a coherent risk measure: application to oil and energy industries", Optimization and Engineering, Vol. 12, No. 1-2, pp. 257275,2011

[20] Q. Xue, Z. Wang, S. Liu, D. Zhao, "An improved portfolio optimization model for oil and gas investment selection", Petroleum Science, Vol. 11, No. 1, pp. 181-188, 2014

[21] Z. Lin, J. Ji, "The portfolio selection model of Oil/Gas projects based on real option theory", in: Lecture Notes in Computer Science, Vol. 4489, pp. 945-952, Springer, Berlin, Heidelberg, 2007

[22] K. Sharma, S. Kumar, "Economic value added (EVA)-literature review and relevant issues", International Journal of Economics and Finance, Vol. 2, No. 2, pp. 200-200, 2010

[23] D. Fountaine, D. J. Jordan, G. M. Phillips, "Using economic value added as a portfolio separation criterion", Quarterly Journal of Finance and Accounting, Vol. 47, No. 2, pp.69-81, 2008

[24] P. Modesti, "EVA and NPV: some comparative remarks", Mathematical Methods in Economics and Finance, Vol. 2, pp. 55-70, 2007

[25] M. Chima, D. Hills, "Supply-chain management issues in the oil and gas industry", Journal of Business \& Economics Research, Vol. 5, No. 6, pp. 27-36, 2011

[26] S. Tordo, B. S. Tracy, N. Arfaa, Natural Oil Companies and Value Creation, World Bank Working Paper No. 218, The World Bank, Washington DC, 2011

[27] Y. Y. Yusuf, A. Gunasekaran, A. Musa, M. Dauda, N. M. El-Berishy, S. Cang, "A relational study of supply chain agility, competitiveness and business performance in the oil and gas industry", International Journal of Production Economics, Vol. 147B, pp. 531-543, 2014

[28] M. S. Peters, K. D. Timmerhaus, R. E. West, Plant Design and Economics for Chemical Engineers, McGraw-Hill Education, 2003

[29] T. Y. Chen, T. C. Ku, "Importance-Assessing Method with Fuzzy Number-Valued Fuzzy Measures and Discussions on TFNs And TrFNs", International Journal of Fuzzy Systems, Vol. 10, No. 2, pp. 92-103, 2008

[30] W. Van Leekwijck, E. E. Kerre, "Defuzzification: criteria and classification", Fuzzy Sets and Systems, Vol. 108, No. 2, pp. 159-178, 1999

[31] Konak, D. W. Coit, A. E. Smith, "Multi-objective optimization using genetic algorithms: A tutorial", Reliability Engineering \& System Safety, Vol. 91, No. 9, pp. 992-1007, 2006

[32] K. Deb, S. Agrawal, A. Pratap, T. Meyarivan, "A fast elitist nondominated sorting genetic algorithm for multi-objective optimization: NSGA-II", Lecture Notes in Computer Science, Vol. 1917, pp. 849-858, Springer, Berlin, Heidelberg, 2000 